\title{
Screening for pulmonary arteriovenous
}

\section{malformations using transthoracic contrast echocardiography: a prospective study}

\author{
M.W.F. van Gent*, M.C. Post*, J.G.L.M. Luermans*, R.J. Snijder”, \\ C.J.J. Westermann", H.W.M. Plokker*, T.T. Overtoom ${ }^{\star}$ and J.J. Mager"
}

ABSTRACT: Pulmonary arteriovenous malformations (PAVMs) are associated with severe neurological complications in patients with hereditary haemorrhagic telangiectasia (HHT). The objective of the present study was to prospectively establish the diagnostic value of transthoracic contrast echocardiography (TTCE) as a screening technique for PAVM using chest highresolution computed tomography (HRCT) as the gold standard for PAVMs.

All consecutive adult patients referred for HHT screening underwent a chest HRCT $(n=299)$, TTCE $(n=281)$, arterial blood gas analysis $(n=291)$, shunt fraction measurement $(n=111)$ and chest radiography $(n=296)$.

TTCE was positive in 87 (58.8\%), 12 (16.7\%) and four (6.7\%) patients, and chest HRCT was positive in $54(36.5 \%)$, three $(4.2 \%)$ and zero (0\%) patients with a definite, possible and negative clinical diagnosis of HHT, respectively. Two patients with a negative TTCE were diagnosed with PAVMs after computed tomography; in both cases the PAVMs were too small to be treated by embolotherapy. The sensitivity of TTCE was $97 \%$ (95\% confidence interval (CI) 93.6-98.3) and negative predictive value $99 \%(95 \% \mathrm{Cl}$ 96.9-99.8). The other diagnostic tests showed a considerable lower diagnostic value.

The present prospective study shows that transthoracic contrast echocardiography has an excellent diagnostic value and can be used as an initial screening procedure for pulmonary arteriovenous malformations. The high false-positive rate of transthoracic contrast echocardiography possibly represents microscopic pulmonary arteriovenous malformations.

KEYWORDS: Contrast echocardiography, hereditary haemorrhagic telangiectasia, pulmonary arteriovenous malformations

pulmonary arteriovenous malformation (PAVM) is a direct communication between a pulmonary artery and pulmonary vein. A PAVM results in a right-to-left shunt (RLS) causing hypoxaemia and risk of paradoxal embolism through bypassing the filtering capillary network. Complications occurring in patients with PAVM and hereditary haemorrhagic telangiectasia (HHT) are stroke (10-19\%), transient ischaemic attacks (6-37\%), cerebral abscess (5-9\%), migraine headaches, seizures, massive haemoptysis and (spontaneous) haemothorax [1-3]. Antibiotic prophylaxis prior to procedures carrying the risk of bacteraemia is recommended [3-5]. At least $80 \%$ of PAVMs are associated with HHT [3]. HHT is an autosomal dominant disorder characterised by vascular abnormalities varying from small telangiectases to large arteriovenous malformations. The clinical diagnosis is based on the Curaçao criteria [6]. Based on genetic analysis, HHT is divided into types 1 and 2, corresponding with mutations in the genes ENG and ACVRL1, coding for endoglin and activin A receptor type-like kinase 1, respectively $[7,8]$. The prevalence of PAVM, as documented by chest high-resolution computed tomography (HRCT), in all HHT patients is 20 $45 \%[4,9]$. The PAVM prevalence differs between these two subtypes, in HHT type 1 the prevalence is $48 \%$, whereas the prevalence in HHT type 2 is $5 \%$ [10]. PAVMs can be effectively treated with transcatheter embolotherapy, which has proven safe and effective in long-term studies [11-18] Recently, it has been proven that embolisation of PAVMs is effective in the prevention of brain abscess and ischaemic stroke if complete occlusion of all PAVMs is achieved [5]. Because of the high incidence of severe complications, early
AFFILIATIONS

Depts of ${ }^{*}$ Cardiology,

\#Pulmonology, and

"Radiology, St Antonius Hospital

Nieuwegein, The Netherlands.

CORRESPONDENCE

M.C. Post

Dept of Cardiology

St Antonius Hospital

Koekoekslaan 1

3435 CM Nieuwegein

The Netherlands

Fax: 31306092274

E-mail: m.post@antonius.net

Received:

March 292008

Accepted after revision:

August 302008

STATEMENT OF INTEREST

None declared. 
diagnosis and if possible, treatment of PAVMs is warranted [3, 5]. Therefore, patients with HHT are routinely screened for PAVMs, even if they are asymptomatic.

\section{Screening for PAVMs}

Screening tests used for detecting PAVMs are chest radiography, arterial oxygen measurement using the $100 \%$ oxygen technique, radionuclide lung scanning, magnetic resonance imaging, pulmonary angiography, chest computed tomography (CT) and transthoracic contrast echocardiography (TTCE). Chest radiography, arterial blood gas analysis, including shunt measurement, using the $100 \%$ oxygen technique and radionuclide scanning lack sensitivity and are not recommended as a single procedure for excluding PAVMs and/or RLS [1, 3, 4]. Chest CT is presently referred to as the gold standard and has shown to be even more accurate than angiography [19]. Pulmonary angiography is indicated only for endovascular treatment of PAVMs [1]. The main disadvantage of CT is radiation exposure. TTCE is a simple, widely available and easy technique that can detect RLS and differentiate between intracardiac and pulmonary shunting. Although there might be concern about complications resulting from paradoxical cerebral air embolism, side-effects of TTCE appear to be rare [20]. Its sensitivity for detecting PAVMs has proven excellent in mainly retrospective studies [4, 21-24]. The aim of the present prospective study is to establish the role of TTCE in screening for PAVM compared with chest CT as gold standard. The current authors hypothesised that TTCE can be used as a single first screening method after which further analysis with chest CT is only recommended for patients in whom TTCE suggests a pulmonary RLS. To the current authors' knowledge, this is the first prospective study systematically examining the screening of PAVM by TTCE compared with chest CT.

\section{METHODS}

\section{Patients}

In total, 317 ( $>16$ yrs of age) consecutive persons were prospectively studied who were referred for possible HHT or were family members of index cases. Screening was performed between May 2004 and June 2007. Almost all patients underwent chest radiography, arterial blood gas analysis, chest CT and TTCE in a 1-day protocol. In addition, on the same day all patients visited a pulmonologist and an otorhinolaryngolist, both experienced in HHT patients. The clinical diagnosis of HHT was established according to the Curaçao criteria [6]. At least three of the following four criteria are required for a clinical diagnosis: spontaneous and recurrent epistaxis: telangiectases at characteristic sites; visceral malformations (PAVM, cerebral arteriovenous malformation, hepatic arteriovenous malformation, or gastrointestinal (GI) telangiectases); and a first degree relative with HHT. In the presence of two criteria, the diagnosis was considered "possible" and the clinical diagnosis was rejected in the presence of one criterion.

All patients were informed by letter about the screening protocol and procedures before visiting the clinic. TTCE is part of the present authors' routine screening protocol for possible HHT patients.

\section{Study objective}

The main objective of the current study was to prospectively establish the diagnostic value of TTCE as a screening technique for PAVM using chest HRCT as the gold standard.

\section{Diagnostic tests}

The arterial oxygen tension $\left(\mathrm{Pa}, \mathrm{O}_{2}\right)$ was measured at rest, breathing room air and an additional shunt measurement breathing $100 \%$ oxygen for $\geqslant 15$ min was performed if $\mathrm{Pa}, \mathrm{O}_{2}$ was $<13 \mathrm{kPa}$ or $<12 \mathrm{kPa}$ for patients younger or older than $30 \mathrm{yrs}$, respectively. The shunt was estimated using the equation:

$$
\mathrm{Q}_{\mathrm{s}} / \mathrm{Q}_{\mathrm{t}}=\left(\mathrm{C}_{\mathrm{c}, \mathrm{O}_{2}}-\mathrm{Ca}_{\mathrm{a}} \mathrm{O}_{2}\right) /\left(\mathrm{C}_{\mathrm{c}, \mathrm{O}_{2}}-\mathrm{C}_{\mathrm{v}}, \mathrm{O}_{2}\right)
$$

in which $Q_{s} / Q_{t}$ is shunt as a fraction of cardiac output, $C_{c}, O_{2}$ is oxygen content at the end of the pulmonary capillary, $\mathrm{Ca}, \mathrm{O}_{2}$ is oxygen content of arterial blood and $\mathrm{C} v, \mathrm{O}_{2}$ is oxygen content of mixed venous blood [25]. Partial pressure of carbon dioxide is assumed to equal partial pressure of oxygen $\left(\mathrm{PO}_{2}\right.$; barometric pressure $(101.3 \mathrm{kPa})$ minus carbon dioxide arterial tension minus alveolar saturated water vapour pressure $\left.\left(P \mathrm{~A}_{1} \mathrm{H}_{2} \mathrm{O}\right)\right)$. $P A, \mathrm{H}_{2} \mathrm{O}$ is $6.3 \mathrm{kPa}$ at a body temperature of $37^{\circ} \mathrm{C}$. Haemoglobin oxygen saturation $\left(\mathrm{SO}_{2}\right)$ at the end of the pulmonary capillary is assumed to be $100 \%$. Oxygen content was calculated as follows:

Oxygen content $=\left(0.0225 \times P_{\mathrm{O}_{2}}\right)+(2.24 \times$ haemoglobin $\times$ $\left.\mathrm{SO}_{2} / 100\right) \mathrm{mL} \mathrm{O}_{2} / 100 \mathrm{~mL}$ blood

$\mathrm{C}_{\mathrm{v}}, \mathrm{O}_{2}$ was assumed to be as defined by the following equation:

$$
\mathrm{C}_{\mathrm{V}}, \mathrm{O}_{2}=\mathrm{Ca}_{1} \mathrm{O}_{2}-4.4 \mathrm{~mL} \mathrm{O}_{2} / 100 \mathrm{~mL} \text { blood }
$$

Using the $100 \%$ oxygen method, a shunt measurement of $>5 \%$ was considered pathological [3, 25].

HRCT scanning (Philips, Best, The Netherlands) of the chest was performed without contrast using the single breath-hold technique with a slice thickness of $1 \mathrm{~mm}$. Both sagittal and coronal reformats were used. Identification of PAVM was based on the presence of a nodular opacity with both an afferent and efferent vessel. A lower limit was not employed for the size of PAVMs. CTs were scored as positive, negative and indeterminate by two independent observers (a radiologist and a pulmonologist experienced in interpreting chest HRCT for the presence of PAVMs) both blinded to the other results of the protocol. In case of disagreement between both observers, the study was considered positive for PAVM. TTCE was performed by three experienced echocardiographers. An intravenous line (18 gauge) was preferentially placed in the right anticubital vein. Two 10-mL syringes were connected, one filled with $8 \mathrm{~mL}$ saline solution and $1 \mathrm{~mL}$ of air. The other syringe was used to draw $1 \mathrm{~mL}$ of blood, which was mixed with the saline-filled syringe by reverse flushing, creating agitated saline (microbubbles). The patient was positioned in the left lateral decubitus position and $10 \mathrm{~mL}$ of the agitated saline was injected while projecting the four-chamber apical view without a Valsalva manoeuvre [21]. TTCE was considered positive for a pulmonary RLS if (one or more) microbubbles appeared in the left atrium after four cardiac cycles [3]. The results were interpreted by a cardiologist without knowledge of the other test results and scored as 
positive, negative or indeterminate (no discrimination possible between patent foramen ovale and pulmonary RLS), or inappropriate for interpretation because of poor quality. Patients in whom the difference between an intracardiac and pulmonary shunt could not be identified were considered positive for the purpose of the analysis. A physician was present at all TTCE studies and checked for possible complications resulting from paradoxical air embolism. Chest CT was referred to as the gold standard for detecting PAVMs in the present study.

\section{Statistical analysis}

Descriptive statistics were used to describe patient characteristics. Continuous variables with normal distribution were presented as mean $\pm \mathrm{SD}$. Median (range) was used when normal distribution was absent. The sensitivity, specificity, positive predictive values (PPV) and negative predictive values (NPV) with their 95\% confidence intervals (CIs) were calculated for each screening test or a combination of two different tests, using the chest CT as the gold standard.

\section{RESULTS}

\section{Study population}

In total, 317 people were screened for possible HHT. From this group, 299 (94\%) persons underwent chest CT scanning, which was regarded as the gold standard for detecting PAVMs. A total of 18 patients refused a chest CT or had a contraindication (e.g. pregnancy). Of all patients who underwent chest CT, chest radiography was performed in 296 (99\%), arterial blood gas analysis in 291 (97\%) and shunt measurement using the 100\% oxygen method in 111 (37\%) patients. TTCE was performed in $283(95 \%)$ patients; in 16 patients placement of an i.v. line failed or was refused. In two patients, TTCE images could not be interpreted because of poor quality. A clinical diagnosis of HHT was definite, possible and rejected in 155 (51.8\%), 80 $(26.8 \%)$ and $64(21.4 \%)$ patients, respectively. These data are summarised in table 1 . The study population available for analysis (both CT and TTCE) consisted of 281 patients with a mean age of $44 \pm 15$ yrs, of whom $61 \%$ were female.

\section{TABLE 1 Baseline characteristics}

\begin{tabular}{|c|c|}
\hline Total n & 299 \\
\hline Females & $183(61.2)$ \\
\hline Age yrs & $44 \pm 15$ \\
\hline \multicolumn{2}{|c|}{ PAVM screening method } \\
\hline HRCT & $299(100)$ \\
\hline TTCE & $281(94)$ \\
\hline Chest radiograph & 296 (99) \\
\hline $\mathrm{Pa}_{1} \mathrm{O}_{2}$ & 291 (97.3) \\
\hline $\mathrm{RLS}^{\#}$ & $111(37.1)$ \\
\hline \multicolumn{2}{|c|}{$\begin{array}{l}\text { Data are presented as } \mathrm{n}(\%) \text { and mean } \pm \mathrm{SD} \text {, unless otherwise stated. PAVM: } \\
\text { pulmonary arteriovenous malformation; HRCT: high-resolution computed } \\
\text { tomography; TTCE: transthoracic contrast echocardiography; } \mathrm{Pa}, \mathrm{O}_{2} \text { : arterial } \\
\text { oxygen tension; RLS: right-to-left shunt. }{ }^{\#}: \text { an } \mathrm{RLS} \text { measured with the } 100 \% \\
\text { oxygen method was only performed if } \mathrm{Pa}, \mathrm{O}_{2} \text { was }<13 \mathrm{kPa} \text { or }<12 \mathrm{kPa} \text { for } \\
\text { patients younger or older than } 30 \text { yrs, respectively. }\end{array}$} \\
\hline
\end{tabular}

\section{Diagnostic value of screening methods}

A chest CT was positive for PAVM in 60 (20.1\%) patients, negative in $238(79.6 \%)$ and indeterminate in one $(0.3 \%)$ patient. The $\kappa$ coefficient for interobserver agreement concerning chest CT was 0.83 . TTCE was positive for a pulmonary RLS in $107(38.1 \%)$ patients. The sensitivity (calculations are based on 281 patients) of TTCE for detecting PAVM was 96.5\% (95\% CI 93.6-98.3) and NPV was 98.9\% (95\% CI 96.9-99.8\%). In contrast, specificity for TTCE was only $76.8 \%$ (95\% CI 71.5 $81.7 \%$ ). In two out of 174 patients with a negative TTCE there was evidence for PAVMs on the chest CT (table 2). In these two patients with a false-negative result, chest CT showed PAVMs that were too small for embolisation therapy (in both patients afferent and efferent vessels were $\leqslant 1 \mathrm{~mm}$ with a venous sac of $3 \mathrm{~mm}$ and $4 \mathrm{~mm}$ diameter, respectively). In one out of these two patients, image quality of the echocardiogram was relatively poor, but was sufficient for correct interpretation. In both of these false-negative patients, $\mathrm{Pa}_{1} \mathrm{O}_{2}$ measurements were below the prespecified threshold, but in neither of them the additional $100 \%$ oxygen method showed a shunt $>5 \%(0.6 \%$ and $1.6 \%$, respectively $)$. Chest radiography was negative in both false-negative patients. In total, 21 (7.5\%) of all patients who underwent echocardiography had signs of a cardiac RLS, of whom two patients met criteria for both a pulmonary and cardiac shunt. In four patients there was doubt whether the RLS was based on a pulmonary or cardiac shunt (detection of contrast material in left atrium at four cardiac cycles).

When combining the TTCE and $\mathrm{Pa}_{1} \mathrm{O}_{2}$ the sensitivity increased to $100 \%$ (95\% CI $98.7-100 \%)$ and the NPV increased to $100 \%$ (95\% CI 98.7-100\%). However, the specificity and PPV decreased to $40.6 \%$ (95\% CI 34.8-46.6\%) and 30\% (95\% CI 24.6-35.6\%), respectively. The sensitivity, specificity, NPV and PPV for each test and the combination of different tests are summarised in table 3 .

TTCE was positive in 87 (58.8\%) out of 148 patients with a definite clinical diagnosis of HHT. In four $(6.7 \%)$ patients without a clinical diagnosis of HHT, TTCE showed a pulmonary shunt and $12(16.7 \%)$ patients with possible HHT

\begin{tabular}{|c|c|c|c|c|}
\hline \multirow[t]{3}{*}{ TABLE 2} & \multicolumn{4}{|c|}{$\begin{array}{l}\text { Transthoracic contrast echocardiography (TTCE) } \\
\text { versus chest high-resolution computed } \\
\text { tomography (HRCT) }\end{array}$} \\
\hline & \multicolumn{4}{|c|}{ HRCT $n$} \\
\hline & Positive & Negative & Indeterminate ${ }^{\#}$ & Total \\
\hline \multicolumn{5}{|l|}{ TTCE $\mathbf{n}$} \\
\hline Positive & 54 & 49 & 0 & 103 \\
\hline Negative & 2 & 171 & 1 & 174 \\
\hline Indeterminate & 1 & 3 & 0 & 4 \\
\hline Total & 57 & 223 & 1 & 281 \\
\hline \multicolumn{5}{|c|}{$\begin{array}{l}\text { \#: the chest HRCT showed small nodules or opacities of uncertain origin, } \\
\text { possibly pulmonary arteriovenous malformations; }{ }^{\prime} \text { : contrast echocardiography } \\
\text { was indeterminate for discrimination between an intracardiac and pulmonary } \\
\text { shunt. }\end{array}$} \\
\hline
\end{tabular}




\begin{tabular}{|c|c|c|c|c|c|c|}
\hline Chest radiography & 296 & $17(5.7)$ & $28.3(23.0-33.5)$ & $100(99.0-100)$ & $84.9(80.2-88.7)$ & $100(99.0-100)$ \\
\hline $\mathrm{Pa}, \mathrm{O}_{2}$ & 291 & $156(53.6)$ & $74.6(69.2-79.5)$ & $51.7(45.6-57.4)$ & $88.9(84.8-92.4)$ & $28.2(23.1-33.7)$ \\
\hline $\begin{array}{l}\text { Shunt using } 100 \% \\
\mathrm{O}_{2}\end{array}$ & 111 & $36(32.4)$ & $77.1(68.6-84.9)$ & $88.2(80.8-93.6)$ & $89.3(81.9-94.3)$ & $75.0(65.7-82.5)$ \\
\hline $\begin{array}{l}\text { TTCE and chest } \\
\text { radiography }\end{array}$ & 298 & $107(38.1)$ & $96.5(93.9-98.4)$ & $61.2(55.3-66.6)$ & $97.9(95.7-99.3)$ & $51.4(45.5-57.2)$ \\
\hline TTCE and $\mathrm{Pa}, \mathrm{O}_{2}$ & 281 & $190(67.6)$ & $100(98.7-100)$ & $40.6(34.8-46.6)$ & $100(98.7-100)$ & $30(24.6-35.6)$ \\
\hline $\begin{array}{l}\text { TTCE and shunt } \\
\text { using } 100 \% \mathrm{O}_{2}\end{array}$ & 281 & $115(40.9)$ & $96.5(93.6-98.3)$ & $73.2(67.7-78.4)$ & $98.8(96.9-99.8)$ & $47.8(41.7-53.7)$ \\
\hline $\begin{array}{l}\text { Chest radiography } \\
\text { and } \mathrm{Pa}_{\mathrm{a}} \mathrm{O}_{2}\end{array}$ & 298 & $157(52.7)$ & $75.0(69.9-80.0)$ & $52.9(47.2-58.6)$ & $89.4(85.2-92.5)$ & $28.7(23.8-34.4)$ \\
\hline
\end{tabular}

Data are presented as $n(\%)$, unless otherwise stated. Cl: confidence interval; NPV: negative predictive value; PPV: positive predictive value; TTCE: transthoracic contrast echocardiography; $\mathrm{Pa}_{\mathrm{a}} \mathrm{O}_{2}$ : partial arterial oxygen pressure. ${ }^{*}$ : includes four patients with an indeterminate shunt (no clear differentiation possible between intracardiac and pulmonary shunt).

also showed positive TTCE. Chest HRCT was positive in 54 $(36.5 \%)$ patients with clinically confirmed HHT and was negative in all patients without HHT. In seven patients, the presence of PAVMs on chest HRCT was required as a criterion for the (definite) clinical diagnosis of HHT (table 4).

\section{DISCUSSION}

The present study shows that TTCE has an excellent NPV for the detection of PAVM. No PAVMs treatable by embolisation were missed using TTCE. Therefore, TTCE can be used as an initial screening technique for PAVM. The high false-positive rate of TTCE may, in part, represent microscopic PAVMs below the detection limit of chest HRCT. In addition, TTCE

\begin{tabular}{|c|c|c|c|c|c|}
\hline \multirow[t]{3}{*}{ TABL } & \multicolumn{5}{|c|}{$\begin{array}{l}\text { Transthoracic contrast echocardiography (TTCE) } \\
\text { and chest high-resolution computed } \\
\text { tomography (HRCT) versus clinical diagnosis of } \\
\text { hereditary haemorrhagic telangiectasia (HHT) }\end{array}$} \\
\hline & & \multicolumn{4}{|c|}{ Clinical diagnosis of HHT } \\
\hline & & Yes & No & Possible & Total \\
\hline \multirow[t]{4}{*}{ TTCE } & Positive & $87(58.8)$ & $4(6.7)$ & $12(16.7)$ & 103 \\
\hline & Negative & 59 (39.9) & $55(90)$ & 60 (83.3) & 174 \\
\hline & Indeterminate & $2(1.3)$ & $2(3.3)$ & 0 & 4 \\
\hline & Total & 148 & 61 & 72 & 281 \\
\hline \multirow[t]{4}{*}{ HRCT } & Positive & $54(36.5)^{\#}$ & 0 & $3(4.2)$ & 57 \\
\hline & Negative & $94(63.5)$ & $61(100)$ & $68(94.4)$ & 223 \\
\hline & Indeterminate & 0 & 0 & $1(1.4)$ & 1 \\
\hline & Total & 148 & 61 & 72 & 281 \\
\hline
\end{tabular}

Data are expressed as $n(\%)$, unless otherwise stated. This table is based on the population screened with both a TTCE and chest HRCT. ${ }^{*}$ : in seven out of 54 patients a definite diagnosis of HHT was based on three Curacao criteria, requiring a pulmonary arteriovenous malformation on chest HRCT as a diagnostic criterion. also appears to be positive in a minority of patients without $\mathrm{HHT}$, suggesting this might partially reflect normal variation in the general population.

Screening for PAVMs in all possible patients with HHT is warranted because of the high incidence of neurological complications in this population. Consensus exists that all PAVMs applicable for intervention should be treated [1]. This strategy is supported by a recent study that demonstrated that no strokes or brain abscesses occurred if obliteration of all angiographically visible PAVMs was achieved [5]. Furthermore, it appeared that the risk for stroke and brain abscess was independent of the severity of PAVMs [5]. TTCE has been studied as a screening technique for PAVMs in retrospective studies [4, 21-24]. Several studies compared TTCE with pulmonary angiography as a gold standard but the numbers of patients were limited and angiography was only performed when TTCE or other screening methods were positive [23, 24, 26]. Therefore, true sensitivity and specificity values remain unknown. COTTIN et al. [4] made an important contribution to the literature on screening for PAVMs in HHT patients. They retrospectively studied 105 HHT patients with TTCE using chest $\mathrm{CT}$ and/or pulmonary angiography as a reference. TTCE proved to have a sensitivity and predictive value for a negative test result of $93 \%$ [4]. TTCE has been proposed as an initial screening test in HHT patients [4, 24, 26, 27]. Chest CT is regarded as the current gold standard for detecting (treatable) PAVMs.

In the current prospective study, the diagnostic value of TTCE was evaluated in comparison with chest $\mathrm{CT}$ as a gold standard in a 1-day protocol in almost 300 subjects. For TTCE, a sensitivity of $97 \%$ and a predictive value for a negative test result of $99 \%$ was found. In two patients TTCE was falsenegative. In both these patients chest CT showed PAVMs that were too small for embolisation therapy. Importantly, therefore, no treatable PAVMs were missed by TTCE. In the present authors' clinic, antibiotic prophylaxis is advised prior to nonsterile procedures in HHT patients, unless a RLS is excluded by TTCE. Consequently, when using TTCE as an 
initial screening method in the present population only two patients $(<1 \%)$ would have been incorrectly denied antibiotic prophylaxis to prevent cerebral abscess. These two patients met all four Curaçao criteria.

As expected, the combination of TTCE with chest radiography did not improve NPV or sensitivity.

The combination of TTCE with $\mathrm{Pa}, \mathrm{O}_{2}$ measurements increased both the sensitivity and NPV to $100 \%$. Patients screened for PAVMs in the present study underwent a $\mathrm{Pa}_{2} \mathrm{O}_{2}$ measurement; shunt measurement was performed if $\mathrm{Pa}_{\mathrm{a}} \mathrm{O}_{2}$ was below the prespecified cut-off value. Both patients with false-negative TTCE appeared to have a low $\mathrm{Pa}_{1} \mathrm{O}_{2}$ (explaining the $100 \%$ sensitivity and NPV when combining TTCE and $\mathrm{Pa}_{2} \mathrm{O}_{2}$ measurement) but subsequent shunt measurement was within normal limits. Therefore, it seems unlikely that pulmonary shunting caused the low $\mathrm{Pa}_{\mathrm{O}_{2}}$ in these patients. As a consequence, the current authors do not think it is justified to conclude that addition of $\mathrm{Pa}_{1} \mathrm{O}_{2}$ measurement to TTCE improves diagnostic accuracy. A sensitivity for a shunt measurement of $77 \%$ and a predictive value for a negative test result of $89 \%$ were found. However, it should be taken into account that shunt measurement was only performed in case of low $\mathrm{Pa}_{1} \mathrm{O}_{2}$ so a lower false-negative rate might be expected and these results should not be considered as representative for the present study population overall. The diagnostic value of this screening test compares negatively with other studies in which a pooled analysis showed a sensitivity of $97.5 \%$ [3]. An explanation for this difference could be the fact that those data were only based on PAVMs large enough for embolisation therapy. COTTIN et al. [4] found a considerably lower sensitivity and negative predictive value $(68 \%$ and $76 \%$, respectively) but performed shunt measurement in all patients.

In the current authors' opinion chest radiography, arterial blood gas analysis and shunt fraction measurement lack diagnostic value as screening methods for PAVM or RLS. However, shunt fraction measurement on $100 \%$ oxygen can be of value in the assessment of the severity of RLS, and in followup after embolotherapy.

When a screening algorithm with TTCE as an initial screening technique (only followed by chest CT if positive) is followed it is of particular importance that none of the treatable PAVMs are overlooked. No PAVMs suitable for embolotherapy were present in the current two patients with false-negative TTCE. In $52(23.2 \%)$ patients, TTCE was positive in the absence of PAVMs on chest CT. In contrast, $172(76.8 \%)$ patients did not have signs of pulmonary RLS and would not undergo chest CT in such a screening algorithm. In the present authors' hospital, this reduces impact on hospital resources and logistics given the fact that TTCE is a simple procedure that consumes little time and expense, but this depends on local facilities and logistics. In only two patients the acoustic window was inadequate for interpretation. However, inability to interpret and correctly judge TTCE outside specialised centres will probably be increased. The latter may reduce the sensitivity of TTCE. No adverse events were experienced as a result of TTCE. However, there may be concern about the risk for paradoxical air embolism. Data about cerebral air embolism are scarce. A survey of 363 physicians performing TTCE revealed neurological and respiratory side-effects in $0.062 \%$ of all procedures, and no residual complications were observed [20]. Other literature regarding this subject is predominantly based on case reports [28-30]. In the current study, $1 \mathrm{~mL}$ of added air was used, but lower volumes of air have become customary in some centres in order to minimise the risk of air embolism. Current guidelines for TTCE still recommend the use of $1 \mathrm{~mL}$ of air [28-31].

Concerns have been raised about the high false-positive rate and, therefore, high costs of TTCE as a screening technique [27]. False-positive might not be an accurate term because a pulmonary RLS seen on TTCE in the absence of PAVMs on chest CT might still represent microscopic PAVMs or telangiectases below the detection limit of CT scanning. This has also been suggested by a study which showed that TTCE frequently remains positive after embolotherapy of PAVMs, even if no residual PAVMs were seen on angiography [23]. Furthermore, microscopic PAVMs were histologically proven in a child with HHT and a pulmonary shunt on echocardiography but without visible PAVMs on chest $\mathrm{CT}$, and in a report of two patients in whom this diagnosis was proven by autopsy [28-33]. However, the present study also shows that TTCE is positive in $6.7 \%$ of patients without a clinical diagnosis of HHT, suggesting that positive TTCE studies, in part, reflect normal variation in the general population.

The influence of postural changes on pulmonary RLS in patients with PAVM (orthodeoxia) has been described in several studies [17, 34-36]. However, COTTIN et al. [4] did not find a different diagnostic value of TTCE in patients in whom echocardiography was performed in both the supine and upright position. The current authors hypothesise that postural changes only influence the degree of shunting and not the diagnosis of a pulmonary RLS per se.

When there is evidence for a PAVM or a pulmonary RLS, antibiotic prophylaxis is recommended prior to procedures carrying risk for bacteraemia [3, 4]. The importance of antibiotic prophylaxis in HHT patients was suggested by SHOVLIN et al. [5], who indentify preceding events known to be associated with bacteraemia in a high proportion of patients with a brain abscess. However, it is not known what impact antibiotic prophylaxis in patients with microscopic PAVMs or telangiectasia might have on neurological sequelae. Data about the follow-up of patients with positive TTCE are lacking. There might be concern that possible microscopic PAVMs could evolve to treatable PAVMs and, therefore, follow-up to detect an opportunity for treatment seems justified. In addition to interpreting TTCE for the presence/absence of a pulmonary shunt, grading of TTCE has been shown to be able to predict the presence of PAVM on chest CT [37]. This modality might further improve the diagnostic value of TTCE.

Given the results of the current prospective study of almost 300 patients, it can be concluded that a screening algorithm for pulmonary arteriovenous malformations in hereditary haemorrhagic telangiectasia patients can be based on initial transthoracic contrast echocardiography, because of its excellent sensitivity and predictive value for a negative test result. If there is evidence for a pulmonary right-to-left shunt on echocardiography, a chest computed tomography is 
performed, in order to detect pulmonary arteriovenous malformations that can be treated by embolisation. Obviously, the preferred screening strategy also depends on local institutional logistics and experience.

\section{REFERENCES}

1 Cottin V, Dupuis-Girod S, Lesca G, Cordier JF. Pulmonary vascular manifestations of hereditary hemorrhagic telangiectasia (Rendu-Osler disease). Respiration 2007; 74: 361-378.

2 Cottin V, Chinet T, Lavole A, et al. Pulmonary arteriovenous malformations in hereditary hemorrhagic telangiectasia: a series of 126 patients. Medicine (Baltimore) 2007; 86: $1-17$.

3 Gossage JR, Kanj G. Pulmonary arteriovenous malformations. A state of the art review. Am J Respir Crit Care Med 1998; 158: 643-661.

4 Cottin V, Plauchu H, Bayle JY, Barthelet M, Revel D, Cordier JF. Pulmonary arteriovenous malformations in patients with hereditary hemorrhagic telangiectasia. Am J Respir Crit Care Med 2004; 169: 994-1000.

5 Shovlin CL, Jackson JE, Bamford KB, et al. Primary determinants of ischaemic stroke/brain abscess risks are independent of severity of pulmonary arteriovenous malformations in hereditary haemorrhagic telangiectasia. Thorax 2008; 63: 259-266.

6 Shovlin CL, Guttmacher AE, Buscarini E, et al. Diagnostic criteria for hereditary hemorrhagic telangiectasia (RenduOsler-Weber syndrome). Am J Med Genet 2000; 91: 66-67.

7 McAllister KA, Grogg KM, Johnson DW, et al. Endoglin, a TGF- $\beta$ binding protein of endothelial cells, is the gene for hereditary haemorrhagic telangiectasia type 1 . Nat Genet 1994; 8: 345-351.

8 Berg JN, Gallione CJ, Stenzel TT, et al. The activin receptorlike kinase 1 gene: genomic structure and mutations in hereditary hemorrhagic telangiectasia type 2. Am J Hum Genet 1997; 61: 60-67.

9 Shovlin CL, Letarte M. Hereditary haemorrhagic telangiectasia and pulmonary arteriovenous malformations: issues in clinical management and review of pathogenic mechanisms. Thorax 1999; 54: 714-729.

10 Post MC, Letteboer TG, Mager JJ, Plokker TH, Kelder JC, Westermann CJ. A pulmonary right-to-left shunt in patients with hereditary hemorrhagic telangiectasia is associated with an increased prevalence of migraine. Chest 2005; 128: 2485-2489.

11 Sabba C, Pasculli G, Lenato GM, et al. Hereditary hemorrhagic telangiectasia: clinical features in ENG and ALK1 mutation carriers. J Thromb Haemost 2007; 5: 11491157.

12 White RI Jr, Pollak JS, Wirth JA. Pulmonary arteriovenous malformations: diagnosis and transcatheter embolotherapy. J Vasc Interv Radiol 1996; 7: 787-804.

13 White RI Jr, Lynch-Nyhan A, Terry P, et al. Pulmonary arteriovenous malformations: techniques and long-term outcome of embolotherapy. Radiology 1988; 169: 663-669.

14 Lee DW, White RI Jr, Egglin TK, et al. Embolotherapy of large pulmonary arteriovenous malformations: long-term results. Ann Thorac Surg 1997; 64: 930-939.

15 Remy-Jardin M, Dumont P, Brillet PY, Dupuis P, Duhamel A, Remy J. Pulmonary arteriovenous malformations treated with embolotherapy: helical CT evaluation of long-term effectiveness after 2-21-year follow-up. Radiology 2006; 239: 576-585.

16 Haitjema TJ, Overtoom TT, Westermann CJ, Lammers JW. Embolisation of pulmonary arteriovenous malformations: results and follow up in 32 patients. Thorax 1995; 50: 719-723.

17 Dutton JA, Jackson JE, Hughes JM, et al. Pulmonary arteriovenous malformations: results of treatment with coil embolization in 53 patients. AJR Am J Roentgenol 1995; 165: 1119-1125.

18 Mager JJ, Overtoom TT, Blauw H, Lammers JW, Westermann CJ. Embolotherapy of pulmonary arteriovenous malformations: long-term results in 112 patients. J Vasc Interv Radiol 2004; 15: 451-456.

19 Remy J, Remy-Jardin M, Wattinne L, Deffontaines C. Pulmonary arteriovenous malformations: evaluation with CT of the chest before and after treatment. Radiology 1992; 182: 809-816.

20 Bommer WJ, Shah PM, Allen H, Meltzer R, Kisslo J. The safety of contrast echocardiography: report of the Committee on Contrast Echocardiography for the American Society of Echocardiography. J Am Coll Cardiol 1984; 3: 6-13.

21 Barzilai B, Waggoner AD, Spessert C, Picus D, Goodenberger D. Two-dimensional contrast echocardiography in the detection and follow-up of congenital pulmonary arteriovenous malformations. Am J Cardiol 1991; 68: 1507-1510.

22 Feinstein JA, Moore P, Rosenthal DN, Puchalski M, Brook MM. Comparison of contrast echocardiography versus cardiac catheterization for detection of pulmonary arteriovenous malformations. Am J Cardiol 2002; 89: 281-285.

23 Lee WL, Graham AF, Pugash RA, et al. Contrast echocardiography remains positive after treatment of pulmonary arteriovenous malformations. Chest 2003; 123: 351-358.

24 Nanthakumar K, Graham AT, Robinson TI, et al. Contrast echocardiography for detection of pulmonary arteriovenous malformations. Am Heart J 2001; 141: 243-246.

25 Mager JJ, Zanen P, Verzijlbergen F, et al. Quantification of right-to-left shunt with ${ }^{99 \mathrm{~m}} \mathrm{Tc}$-labelled albumin macroaggregates and $100 \%$ oxygen in patients with hereditary haemorrhagic telangiectasia. Clin Sci (Lond) 2002; 102: 127-134.

26 Kjeldsen AD, Oxhoj H, Andersen PE, Elle B, Jacobsen JP, Vase P. Pulmonary arteriovenous malformations: screening procedures and pulmonary angiography in patients with hereditary hemorrhagic telangiectasia. Chest 1999; 116: 432-439.

27 Gossage JR. The role of echocardiography in screening for pulmonary arteriovenous malformations. Chest 2003; 123: 320-322.

28 Christin F, Bouffard Y, Rossi R, Delafosse B. Paradoxical symptomatic air embolism after saline contrast transesophageal echocardiography. Echocardiography 2007; 24: 867-869.

29 Holcomb BW, Loyd JE, Byrd BF 3rd, et al. Iatrogenic paradoxical air embolism in pulmonary hypertension. Chest 2001; 119: 1602-1605.

30 Srivastava TN, Undesser EK. Transient ischemic attack after air contrast echocardiography in patients with septal aneurysm. Ann Intern Med 1995; 122: 396. 
31 Attaran RR, Ata I, Kudithipudi V, Foster L, Sorrell VL. Protocol for optimal detection and exclusion of a patent foramen ovale using transthoracic echocardiography with agitated saline microbubbles. Echocardiography 2006; 23: 616-622.

32 Mache CJ, Gamillscheg A, Popper HH, Haworth SG. Earlylife pulmonary arterial hypertension with subsequent development of diffuse pulmonary arteriovenous malformations in hereditary haemorrhagic telangiectasia type 1. Thorax 2008; 63: 85-86.

33 Hales MR. Multiple small arteriovenous fistulae of the lungs. Am J Pathol 1956; 32: 927-943.

34 Terry PB, White RI Jr, Barth KH, Kaufman SL, Mitchell SE. Pulmonary arteriovenous malformations. Physiologic observations and results of therapeutic balloon embolization. N Engl J Med 1983; 308: 11971200.

35 Thompson RD, Jackson J, Peters AM, Dore CJ, Hughes JM. Sensitivity and specificity of radioisotope right-left shunt measurements and pulse oximetry for the early detection of pulmonary arteriovenous malformations. Chest 1999; 115: 109-113.

36 Ueki J, Hughes JM, Peters AM, et al. Oxygen and ${ }^{99 \mathrm{~m}} \mathrm{Tc}-$ MAA shunt estimations in patients with pulmonary arteriovenous malformations: effects of changes in posture and lung volume. Thorax 1994; 49: 327-331.

37 Zukotynski K, Chan RP, Chow CM, Cohen JH, Faughnan ME. Contrast echocardiography grading predicts pulmonary arteriovenous malformations on CT. Chest 2007; 132: 18-23. 